\title{
Analisa dan Pengembangan Aplikasi Sentralisasi Kas Cash Deposit Machine
}

\author{
Muhammad Feizal \\ Teknik Informatika, Universitas Pamulang \\ Email: muh.feizal@yahoo.com
}

\begin{abstract}
Abstrak
CDM atau Cash Deposit Machine adalah sebuah perangkat keras yang disediakan oleh bank untuk digunakan oleh nasabah sebagai wahana atau stasiun penyetoran uang tunai. Sistem pencatatan Cash Deposit Machine yang terjadi selama ini, dilakukan dan dimaintain oleh pihak cabang, sehingga monitoring terhadap pencatatan tersebut menjadi lebih sulit dan membutuhkan sdm yang lebih banyak. Dilihat dari latar belakang dan permasalahan diatas, maka perlu dibuat sentralisasi Kas CDM agar mempermudah pencatatan dan penggunaan transaksi yang masuk melalui Cash Deposit Machine. Selain itu diharapkan sistem sentralisasi Kas CDM ini dapat memperkecil effort yang dikeluarkan oleh Bagian Operasional dalam mendukung operasional Cash Deposit Machine. Metode yang digunakan adalah studi referensi dan perancangan untuk mempelajari informasi yang didapat dari berbagai sumber serta menjadikannya dasar dalam pengembangan aplikasi. Dengan adanya inisiatif dan aplikasi yang dapat melakukan sentralisasi Kas CDM ini dapat memberikan efisiensi dan efektifitas dalam melakukan pengelolaan Cash Deposit Machine.
\end{abstract}

Kata Kunci: Cash Deposit Machine, Sentralisasi Kas, Bank

\section{Pendahuluan}

CDM atau Cash Deposit Machine adalah sebuah perangkat keras yang disediakan oleh bank untuk digunakan oleh nasabah sebagai wahana atau stasiun penyetoran uang tunai.

Selama ini masyarakat sudah terbiasa dengan sistem transaksi setor tunai melalui Teller.

Diharapkan dimasa yang akan datang teknologi Cash Deposit Machine dapat menjadi ujung tombak perbankan dalam mengembangkan bisnisnya.

\section{Metode Penelitian}

CDM atau Cash Deposit Machine adalah mesin ATM yang dapat menerima setoran tunai dan inquiry saldo rekening. Bentuk Cash Deposit Machine hampir sama dengan ATM biasa, namun pada sisi depan terdapat lubang / laci untuk meletakkan uang yang akan disetor. Untuk melakukan setoran tunai, nasabah harus menggunakan kartu Debit Bank dan nomor PIN yang sama dengan yang digunakan pada mesin ATM biasa.

\section{Tipe Transaksi}

Cash Deposit Machine memiliki beberapa tipe transaksi. Seperti halnya transaksi tunai yang dilakukan melalui Teller, hal-hal yang dapat terjadi pada transaksi tunai melalui Teller, juga dapat terjadi melalui CDM.
Dari pengalaman pengimplementasian CDM, dapat diketahui bahwa transaksi CDM memiliki dua jenis transaksi besar, yaitu transaksi berhasil dan transaksi gagal. Transaksi gagal disebabkan karena:

1. Uang tunai dibaca oleh mesin sebagai uang palsu.

2. Uang tunai rusak atau terlipat.

3. Kesalahan/error sistem.

Untuk setiap transaksi yang dianggap berhasil oleh mesin masih bisa terjadi kesalahan atau selisih perhitungan. Salah satu contoh penyebabnya adalah uang palsu yang lolos dari pengecekan CDM.

Oleh karena itu Bank perlu mencegah agar selisih perhitungan dapat diminimalisir. Salah satu cara adalah dengan membuat sistem yang memungkinkan dilakukannya koreksi transaksi.

Dari penjelasan diatas, maka dapat disimpulkan aplikasi sentralisasi Kas CDM ini harus memiliki kemampuan untuk mencatat transaksi yang berhasil maupun transaksi berhasil yang mengalami koreksi/reversal. Sehingga dapat digambarkan dalam use case diagram adalah sebagai berikut: 


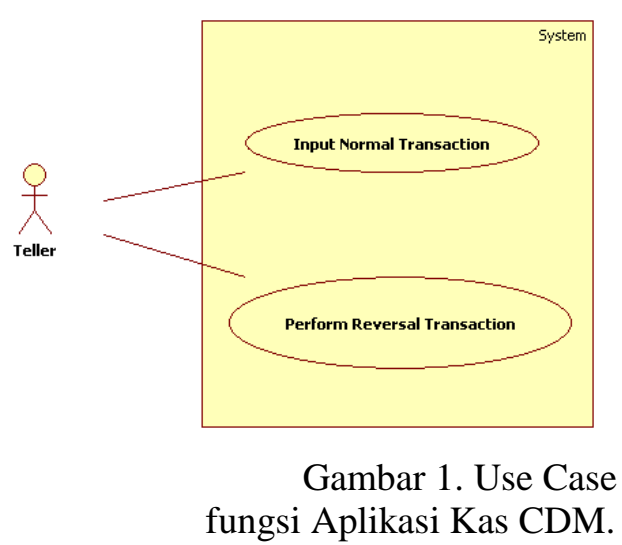

Alur Aplikasi

Aplikasi sentralisasi kas cdm melibatkan dua jenis aplikasi yaitu:

1. Aplikasi Teller, yang merupakan aplikasi front-end.

2. Gateway, merupakan aplikasi perantara antara front-end dengan core-banking.

Alur proses dari aplikasi Kas CDM ini adalah sebagai berikut:

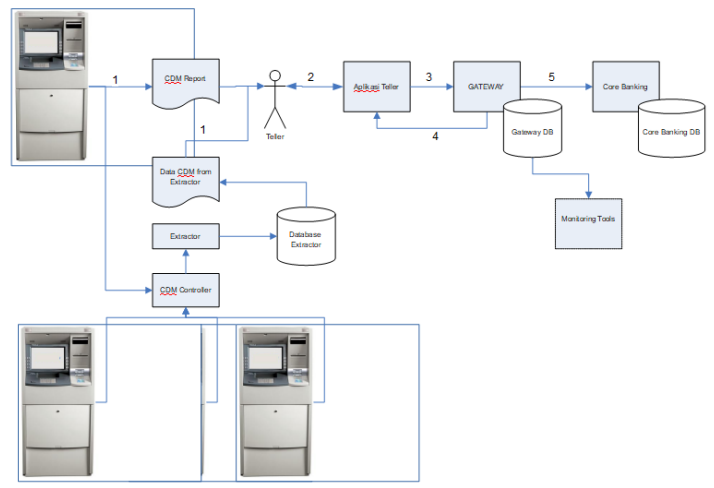

Gambar 2. Arsitektur Aplikasi Kas CDM

Penjelasan untuk gambar diatas adalah sebagai berikut:

1. Teller akan mencocokan antara laporan jumlah pengumpulan fisik uang dari mesin CDM dengan Data CDM yang diterima oleh Extractor.

2. Teller akan melakukan pembukuan melalui Aplikasi Teller

3. Data yang diinput melalui Aplikasi Teller diinput ke database Gateway melalui Gateway.

4. Apabila terjadi error maka akan ditampilkan pesan error ke Aplikasi Teller.

5. Data transaksi yang berhasil akan dilanjutkan pembukuan ke Core Banking.
Apabila ada selisih antara laporan jumlah uang yang didapat dari CDM Report, dengan Data dari Extractor, maka Teller akan melakukan transaksi pembukuan selisih kurang.

Sedangkan aliran aktifitas pemakaian aplikasi sentralisasi kas CDM dapat dilihat dibawah ini.

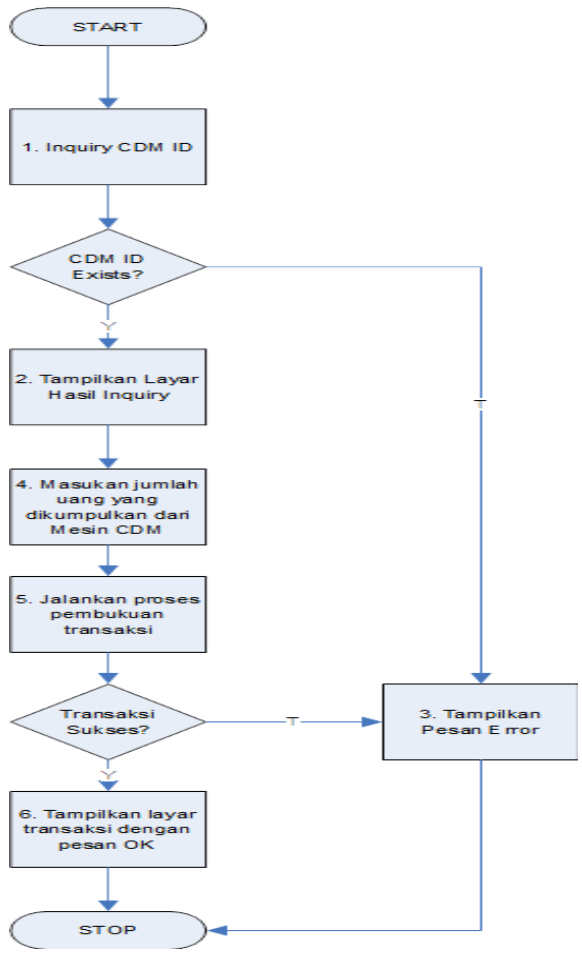

Gambar 3. Flowchart Transaksi Normal Aplikasi Kas CDM

Penjelasan Alur Transaksi Normal:

1. Teller melakukan inquiry berdasarkan CDM ID.

2. Apabila CDM ID ditemukan maka ditampilkan hasil inquiry.

3. Apabila tidak ditemukan akan ditampilkan pesan error.

4. Setelah hasil inquiry ditampilkan, Teller memasukkan jumlah uang yang dikumpulkan dari mesin CDM kedalam field nominal dan Uraian keterangan.

5. Kemudian dari Aplikasi Teller akan dilakukan pembukan transaksi kedalam database Core Banking.

6. Setelah sukses dilakukan pembukan kedalam database Core Banking, maka dilakukan juga pencatatan log kedalam database Kas CDM di gateway. 


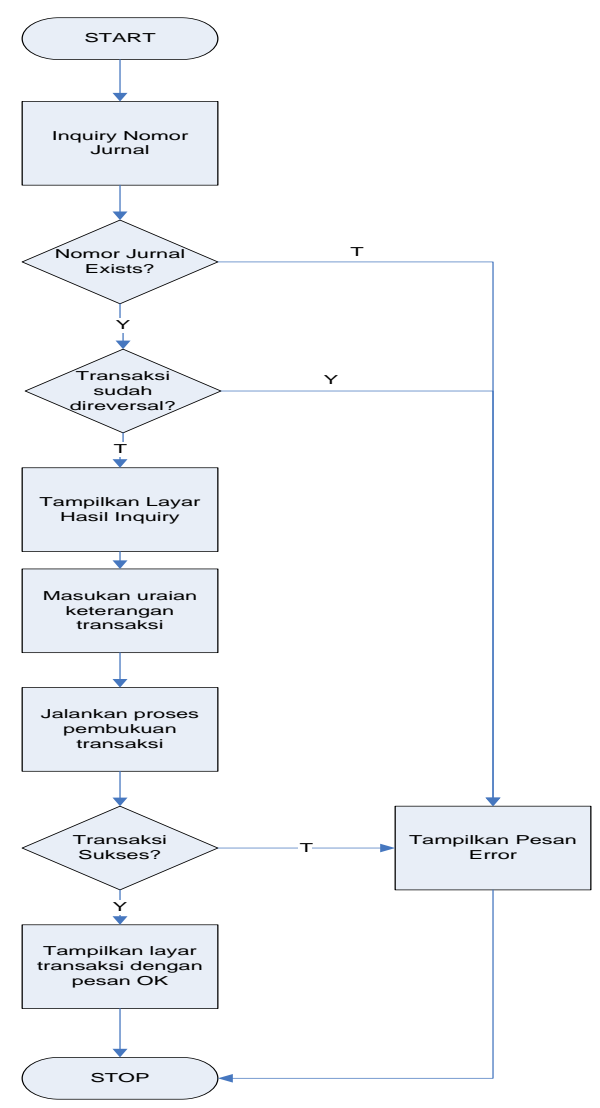

Gambar 4. Flowchart Transaksi Reversal Aplikasi Kas CDM

Penjelasan Alur Transaksi Reversal:

1. Teller melakukan inquiry nomor jurnal yang akan direversal.

2. Apabila nomor jurnal ditemukan, maka dilihat status reversal dari transaksi tersebut. Apabila status reversal belum terisi, maka tampilkan hasil inquiry. Data hasil inquiry yang ditampilkan adalah Nomor Jurnal, CDM ID, Lokasi CDM, Nomor Rekening Kas CDM dan Nominal.

3. Apabila nomor jurnal tidak ditemukan maka ditampilkan pesan error. Begitu juga, apabila status reversal sudah terisi, berarti transaksi tersebut sudah direversal, maka selanjutnya ditampilkan pesan error.

4. Kemudian dari Aplikasi Teller akan dilakukan pembukuan transaksi kedalam database Core Banking.

5. Setelah sukses dilakukan pembukuan kedalam database Core Banking, maka dilakukan juga pencatatan log kedalam database Kas CDM yang berada di gateway.

6. Data yang dimasukkan kedalam log database di Gateway termasuk nomor jurnal referensi dan status reversal. Nomor jurnal dan status reversal ini digunakan sebagai penanda, sehingga transaksi yang sudah direversal tidak dapat direversal kembali.

\subsection{Mekanisme Pembukuan}

Pembagian tipe pembukuan dari satu flow penuh transaksi CDM dapat digambarkan sebagai berikut:

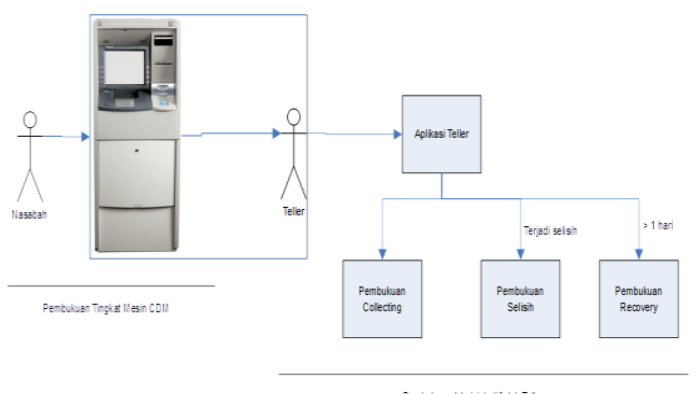

Gambar 5. Pembagian Pembukuan Transaksi

Deskripsi mekanisme pembukuan dari masing-masing tipe transaksi adalah sebagai berikut:

1. Pembukuan Tingkat Mesin CDM. Untuk pembukuan transaksi tingkat mesin CDM tidak masuk kedalam aplikasi Sentralisasi Kas CDM. Pembukuan ini terjadi pada saat nasabah melakukan setoran. Rincian pembukuannya adalah:

a. Transaksi yang dilakukan pada CDM oleh nasabah dari Cabang Pemilik CDM.

b. Transaksi yang dilakukan pada CDM oleh Nasabah bukan dari Cabang Pemilik CDM.

2. Pembukuan Collecting.

Untuk pembukuan transaksi normal collecting dilakukan pada saat seluruh jumlah uang dari CDM yang ada di cabang dikumpulkan/collect.

3. Pembukuan Selisih Kurang.

Pembukuan selisih kurang dijalankan apabila ditemukan adanya selisih jumlah. Pembukuan ini berfungsi mencatat pembukuan selisih tersebut. Kemudian dilanjutkan dengan pembukuan rekening Beban.

4. Pembukuan Recovery

Pembukuan recovery dilakukan pada saat penyebab dari terjadinya selisih uang sudah diketahui. 


\section{Pembahasan}

Salah satu aplikasi yang perlu dikembangkan untuk mengakomodir sentralisasi Kas CDM ini adalah aplikasi Teller. Aplikasi Teller akan digunakan oleh teller untuk memasukkan data-data transaksi. Daftar menu dan layar yang digunakan dapat dilihat dalam tabel dibawah ini:

Tabel 1. Menu dan Layar Aplikasi Teller untuk Kas CDM

\begin{tabular}{|c|c|c|}
\hline \multicolumn{3}{|c|}{ MENU BARU } \\
\hline \multicolumn{3}{|c|}{ KAS CDM } \\
\hline \multicolumn{3}{|c|}{ PEMBUKUAN CDM } \\
\hline \multicolumn{3}{|r|}{ Collecting CDM } \\
\hline \multicolumn{3}{|r|}{ Selisih Kurang Karena Uang Palsu } \\
\hline & & Pembebanan Cabang Karena Uang Palsu \\
\hline & & Pembukuan Rekg Memorial Debet Beban Cabang \\
\hline \multicolumn{3}{|r|}{ Recovery Selisih Kurang Karena Uang Palsu } \\
\hline & & Recovery Beban Cabang \\
\hline & & Pembukuan Rekg Kredit Recovery Beban Cabang \\
\hline \multicolumn{3}{|r|}{ Selisih Kurang Karena Masalah Error Sistem } \\
\hline & & Pembebanan Cabang Karena Error Sistem \\
\hline & & Pembukuan Rekg Debet Recovery Beban Cabang \\
\hline \multicolumn{3}{|r|}{ Recovery Selisih Kurang Karena Error Sistem } \\
\hline & & Recovery Beban Cabang \\
\hline & & Pembukuan Rekg Kredit Recovery Beban Cabang \\
\hline \multicolumn{3}{|c|}{ REVERSAL CDM } \\
\hline & & Reversal Collecting CDM \\
\hline & & Reversal Selisih Kurang Karena Uang Palsu \\
\hline & & Reversal Pembebanan Cabang Karena Uang Palsu \\
\hline & & Reversal Pembukuan Rekg Debet Recovery Beban Cabang \\
\hline & & Reversal Recovery Selisih Kurang Karena Uang Palsu \\
\hline & & Reversal Recovery Beban Cabang \\
\hline & & Reversal Pembukuan Rekg Kredit Recovery Beban Cabang \\
\hline & & Reversal Selisih Kurang Karena Masalah Error Sistem \\
\hline & & Reversal Pembebanan Cabang Karena Error Sistem \\
\hline & & Reversal Pembukuan Rekg Debet Recovery Beban Cabang \\
\hline & & Reversal Recovery Selisih Kurang Karena Error Sistem \\
\hline & & Reversal Recovery Beban Cabang \\
\hline & & Reversal Pembukuan Rekg Kredit Beban Cabang \\
\hline
\end{tabular}

Tampilan layar transaksi collecting CDM adalah sebagai berikut:

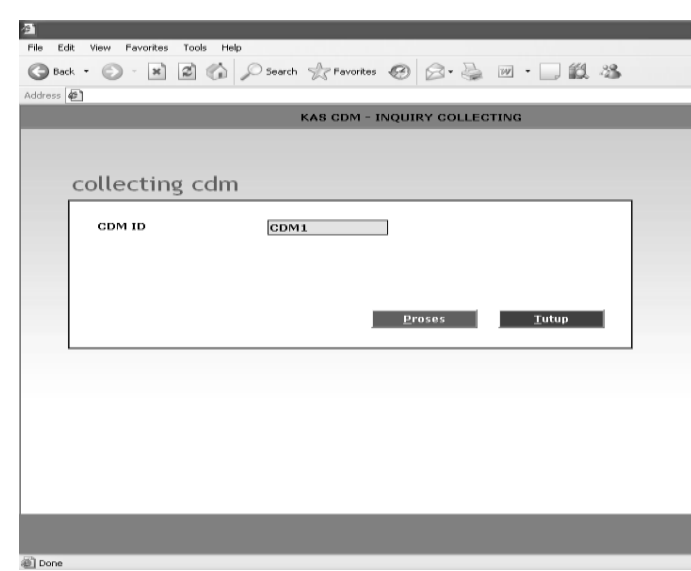

Gambar 6. Layar inquiry transaksi normal CDM

Setelah memasukkan CDM ID dan user menekan tombol process, maka gateway akan mencari informasi mengenai CDM ID tersebut ke database, dan menampilkannya ke layar berikutnya. Tampilan hasil inquiry tersebut adalah sebagai berikut:

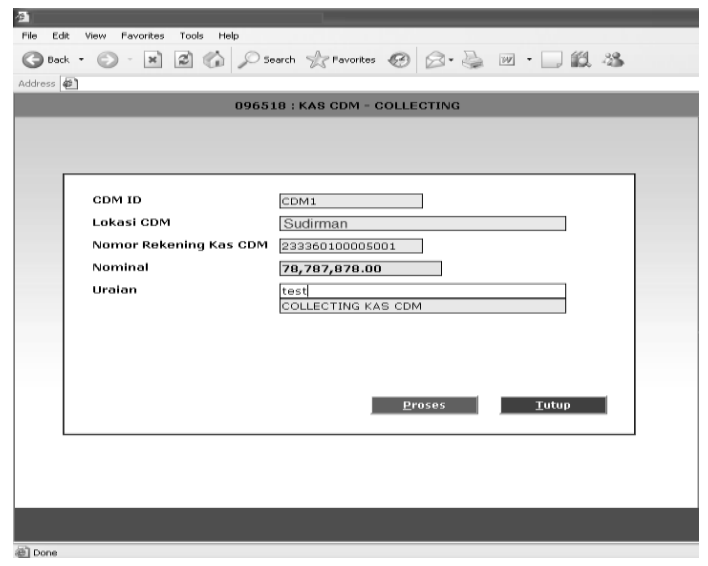

Gambar 7. Layar hasil inqury transaksi normal CDM.

Setelah layar hasil inquiry ditampilkan selanjutnya user memasukkan nominal yang akan ditransaksikan, beserta uraiannya, untuk kemudian dilakukan pembukuan dengan cara menekan tombol proses.

Apabila terjadi selisih antara fisik uang yang dikumpulkan dengan data yang berasal dari Extractor, maka dilakukan transaksi pembukuan tambahan berupa transaksi selisih kurang. Setelah diketahui sumber selisih uang, maka dilakukan recovery terhadap transaksi selisih tersebut.

\section{Transaksi Reversal}

Menu transaksi reversal diaplikasi Teller ditempatkan terpisah dari transaksi normalnya. Secara tampilan, layar transaksi reversal memiliki beberapa kemiripan dengan transaksi 
normal. Untuk layar inquiry transaksi reversal adalah sebagai berikut:

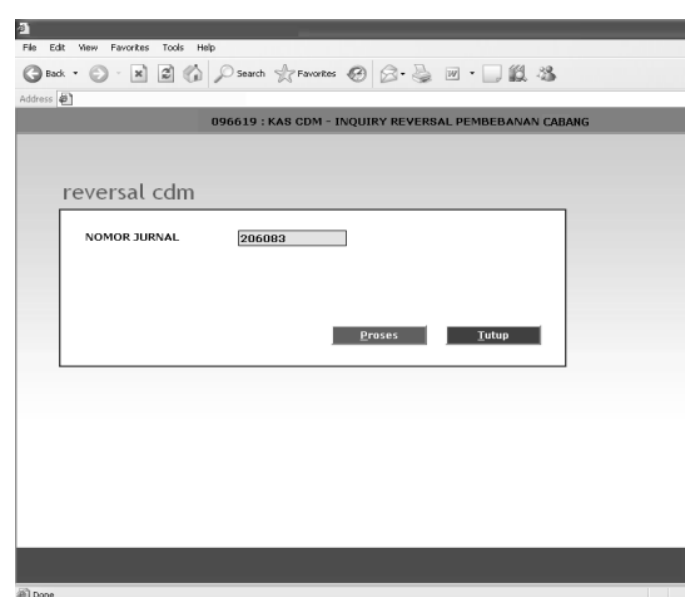

Gambar 8. Layar inquiry transaksi reversal CDM.

Untuk melakukan reversal, user memasukkan nomor jurnal dari transaksi yang akan direversal. Kemudian nomor jurnal tersebut akan dicari ke dalam database log di gateway. Apabila nomor jurnal tersebut ditemukan didalam database maka hasil inquiry tersebut ditampilkan dihalaman selanjutnya. Layar hasil inquiry transaksi reversal adalah sebagai berikut:

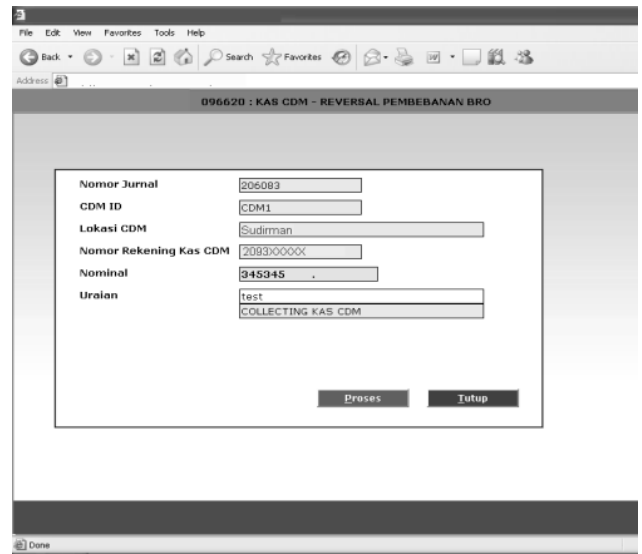

Gambar 9. Layar hasil inquiry transaksi reversal CDM.

Setelah layar hasil inquiry ditampilkan, user hanya perlu menambahkan deskripsi transaksi didalam field uraian, untuk kemudian dilakukan pembukuan dengan cara menekan tombol proses.

\section{Pengembangan Aplikasi Gateway}

Fungsi dan peran gateway disini adalah untuk menyampaikan dan mentransformasikan message transaksi yang dikirim melalui aplikasi
Teller, untuk kemudian dikirim ke Core Banking dan dilakukan pembukuan.

Sebagian besar transaksi yang ada pada aplikasi Kas CDM ini menggunakan format message dari transaksi-transaksi yang sudah ada, diantaranya adalah format message untuk setoran tunai, penarikan tunai, pemindah bukuan dan pemindahan dari simpanan

\section{Kesimpulan}

Aplikasi sentralisasi kas CDM merupakan aplikasi yang berfungsi menunjang penggunaan Cash Deposit Machine.

Dengan adanya aplikasi Teller dan Gateway CDM diharapkan dapat memberikan nilai tambah secara langsung dalam:

1. Efisiensi penggunaan sumberdaya manusia untuk melakukan pembukan transaksitransaksi yang masuk melalui CDM.

2. Effort yang lebih kecil untuk melakukan monitoring terhadap pencatatan transaksi kas cdm dibandingkan dengan sistem pencatatan yang terdistribusi.

3. Mempermudah proses pelacakan, apabila terjadi kesalahan pencatatan dan proses reversal terhadap kesalahan transaksi juga lebih mudah, karena hanya dilakukan pada satu titik.

4. Mempermudah proses backup dan restore terhadap data-data transaksi mesin CDM yang tersebar dicabang-cabang.

Selain nilai tambah secara langsung, aplikasi sentralisasi Kas CDM ini juga memberikan manfaat secara tidak langsung bagi Bank:

1. Aplikasi sentralisasi kas cdm ini memberikan peningkatan efisiensi dan kemudahan dalam implementasi Cash Deposit Machine.

2. Implementasi CDM yang sudah mature akan membawa CDM sebagai jalur alternatif bagi nasabah untuk menambah alokasi dananya ke bank, dan membuka peluang untuk peningkatan DPK (Dana Pihak Ketiga).

3. Apabila mayoritas nasabah sudah menggunakan CDM maka biaya operasional dari cabang akan berkurang. Hal ini disebabkan karena fungsi Teller dapat dialihkan ke CDM.

\section{Saran}

Untuk pengembangan selanjutnya diharapkan transaksi-transaksi yang dapat diotomatisasi oleh Core Banking, dapat 
dilakukan langsung oleh Core Banking. Contohnya adalah transaksi pembukuan ke rekening recovery beban cabang dalam kasus transaksi koreksi. Hal ini dapat mengurangi jumlah menu di aplikasi Teller dan mengurangi pekerjaan Teller dalam memasukkan data ke layar aplikasi Teller, serta meminimalisir data yang tidak lengkap, tidak valid atau transaksi yang terlewat.

\section{Referensi}

Issarny, V. Caporuscio, M. Georgantas, N. A Perspective on the Future of Middleware-based
Software Engineering. Future of Software Engineering. 1-5

Kepfer, C. Tanoto, W. Zhang, B \& Sim. M, 2007. The ATMs, Cash Dispensing and Retail Payments Report 2007. Asian Banker Research Maret 2007. $16-22$

Schoofs, M. ATMs Become Handy Tool For Laundering Dirty Cash. https://www.wsj.com/articles/SB1190332669477 34601 